\title{
Testing the Opportunistic Approach to Monetary Policy
}

\author{
Christopher Martin \\ Department of Economics and Finance, \\ Brunel University \\ Uxbridge \\ Middlesex UB8 3PH \\ UK \\ and \\ Costas Milas* \\ Department of Economics, \\ Keele University \\ Staffordshire, ST5 5BG \\ UK
}

October 2006

\begin{abstract}
The Opportunistic Approach to Monetary Policy is an influential but untested model of optimal monetary policy. We provide the first tests of the model, using US data from 1983Q1-2004Q1. Our results support the Opportunistic Approach. We find that policymakers respond to the gap between inflation and an intermediate target that reflects the recent history of inflation. We find that there is no response of interest rates to inflation when inflation is within $1 \%$ of the intermediate target but a strong response when inflation is further from the intermediate target.
\end{abstract}

\section{JEL: C51; C52; E52; E58}

Keywords: monetary policy, zone of discretion, intermediate inflation target.

${ }^{*}$ Corresponding author: Costas Milas, Department of Economics, Keele University, Keele, ST5 5BG, United Kingdom.

Phone: +44 (0) 1782 583090. Fax: +44 (0) 1782717577.

Email: c.milas@keele.ac.uk

We thank Athanasios Orphanides, Simon van Norden, John C. Williams, Gary Koop, Julia Darby and seminar audiences at Brunel and Strathclyde Universities for useful comments and suggestions. We are also grateful to Kalvinder Shields for making the real-time output data used in the Garratt, Lee, Mise and Shields (2005) working paper available to us. 
Testing the Opportunistic Approach to Monetary Policy

\section{Introduction}

Empirical models of monetary policy are widely used to study interest rates and to investigate the objectives of policymakers. The great majority of studies use the Taylor rule (Taylor, 1993). This is a simple linear relationship in which desired real interest rates adjust in each period to eliminate a fixed proportion of the gap between actual and desired values of inflation and output. Recently, however, there has been increasing dissatisfaction with the Taylor rule. In part, this is due to concerns about whether Taylor rules are optimal, as some authors argue that policymakers can do better by following alternative rules (e.g.

Svensson, 2003). But there are also concerns that the Taylor rule is too restrictive, suggesting that a more sophisticated approach to the empirical modeling of monetary policy may provide new insights. Given the importance of models of monetary policy to the academic and wider policy communities, evaluation of these alternative approaches is important.

One possible alternative is the Opportunistic Approach to Monetary Policy (Opportunistic Approach), developed by Orphanides and Wilcox (2002) and Aksoy et al (2005). Originally prompted by comments by members of the Federal Open Market Committee, the Opportunistic Approach has two main features. The best-known feature is the argument that policymakers should take aggressive action when inflation is some way from its desired level but should otherwise give greater priority to output. This is formalized using the concept of 
the zone of discretion, a range of values for the inflation rate around the desired rate. It is argued that policymakers should raise real interest rates when inflation is above the zone of discretion and cut real interest rates when inflation is below the zone. When inflation is inside the zone, policymakers should behave opportunistically by accommodating shocks that tend to move inflation towards the desired level but not otherwise responding to shocks until the boundaries of the zone of discretion are reached. A second feature of the approach is the argument that policymakers should attempt to move inflation towards an intermediate inflation target that reflects both the desired inflation rate (or inflation target) and the inflation rate inherited from the previous period.

This approach implies a more subtle response to macroeconomic events than with the linear Taylor rule. Policymakers respond aggressively when inflation threatens to move some way from the desired level but respond more passively when inflation only deviates from the desired level by a smaller amount. Arguably, the Opportunistic Approach also has similarities with "constrained discretion" as advocated by Bernanke and Mishkin (1997) and Bernanke $(2003)^{1}$. Thus far, the literature has viewed the Opportunistic Approach as a recommendation for how policymakers ought to behave rather than as a description of how policymakers have actually behaved in practice. This paper, by contrast, will examine whether policymakers' behavior has been consistent with the Opportunistic Approach.

\footnotetext{
${ }^{1}$ As described by Bernanke (2003), constrained discretion consists of "a strong commitment to low and stable inflation" and, subject to this, "striving to limit cyclical swings in resource utilisation".
} 
We begin by testing whether policymakers have been using an intermediate inflation target. Doing this requires only a slight extension of the familiar Taylor rule model of monetary policy. We then assess the prediction that policymakers respond more aggressively when inflation is outside the zone of discretion by considering the model of the Opportunistic Approach proposed by Aksoy et al (2005). This requires a three-regime model in which the behavior of interest rates depends on whether inflation is expected to be within, above or below the zone of discretion. We assess the suitability of such a model by testing the previously estimated Taylor rule for the effects of neglected nonlinearity, using a test that is known to be sensitive to the type of nonlinearity implied by the Opportunistic Approach. We then present estimates of the model before considering related models that relax some of the assumptions of the model of Aksoy et al (2005).

We estimate our models using US data for the period 1983Q1-2004Q1 and using real-time output data. We find strong empirical support for the Opportunistic Approach. Introducing an intermediate inflation target into an otherwise standard Taylor rule improves the fit of the model. The structural nonlinear model implied by the Opportunistic Approach fits the data better than a Taylor rule. In our preferred model, a slightly amended version of the model of Aksoy et al (2005), we find that the zone of discretion is symmetric, extending from $1 \%$ below the desired inflation rate to $1 \%$ above. These estimates suggest that key features of the Opportunistic Approach are reflected in the behavior of policymakers. 
The remainder of the paper is structured as follows. Section 2 outlines the model of Orphanides and Wilcox (2002) and Aksoy et al (2005) and suggests how it might be estimated. Section 3 presents estimates of a Taylor rule, a Taylor rule augmented by an intermediate inflation target and the model of Aksoy et al (2005), arguing that the latter model is not superior to the augmented Taylor rule. Section 4 suggests how some of the restrictions imposed by the model of Aksoy et al (2005) might be relaxed and presents estimates that suggest this modified model provides the best fit to the data. Section 5 reports estimates based on alternative measures of the data. Section 6 discusses the implications of the opportunistic approach. Section 7 summarizes and concludes.

\section{Foundations of the Opportunistic Approach to Monetary Policy}

Orphanides and Wilcox (2002) analyse the model ${ }^{2}$

(1) $\quad L=\left(\pi-\pi^{I}\right)^{2}+\gamma y^{2}+\psi a b s(y)$

(2) $\quad \pi_{t}=\pi^{e}+\alpha y_{t}+\varepsilon_{s t}$

$$
y_{t}=\sigma_{0}-\sigma\left(r_{t}-r^{*}\right)+\varepsilon_{d t}
$$

\footnotetext{
${ }^{2}$ Minford and Srinivasan (2006) develop an alternative theoretical model of opportunistic behavior relying on adaptive expectations and asymmetry in the Phillips curve.
} 
where $\pi$ is the inflation rate, $\pi^{\prime}$ is the intermediate inflation target, $y$ is the output gap, $\pi^{\mathrm{e}}$ is expected inflation, $r$ is the real interest rate, $r^{*}$ is the equilibrium real interest rate, $\alpha, \sigma_{0}$ and $\sigma$ are positive parameters, $\varepsilon_{\mathrm{s}}$ is a supply shock and $\varepsilon_{\mathrm{d}}$ is a demand shock.

Equation (1) describes the loss function of policymakers. The loss from inflation is a quadratic function of the difference between inflation and the intermediate inflation target. The loss from output includes a linear function of the absolute value of the output gap. Equation (2) is a static expectationsaugmented Phillips curve while equation (3) is a simple, static aggregate demand relationship. Assuming that policymakers choose the optimal interest rate for period $t$ at the end of period (t-1) using information available up to the end of period (t-1), the optimal monetary policy rule proposed in Orphanides and Wilcox (2002) is then

$$
\left\{\begin{array}{c}
i_{t}=i^{*}+\rho_{Z D} E_{t-1}\left(\pi_{t}-\pi^{I}{ }_{t}\right)+\rho_{y} E_{t-1} y_{t} \\
\text { if }\left\{-\delta \leq E_{t-1}\left(\pi_{t}-\pi^{I}{ }_{t}\right) \leq \delta\right\} \\
i_{t}=i^{*}+\rho_{O Z D} E_{t-1}\left(\pi_{t}-\pi^{I}{ }_{t}+\delta\right)+\rho_{y} E_{t-1} y_{t} \\
\text { if }\left\{-\delta>E_{t-1}\left(\pi_{t}-\pi^{I}\right)\right\} \\
i_{t}=i^{*}+\rho_{O Z D} E_{t-1}\left(\pi_{t}-\pi^{I}{ }_{t}-\delta\right)+\rho_{y} E_{t-1} y_{t} \\
\text { if }\left\{\delta<E_{t-1}\left(\pi_{t}-\pi^{I}{ }_{t}\right)\right\}
\end{array}\right\}
$$

where $i^{\star}$ is the equilibrium nominal interest rate. Equation (4) is a non-linear monetary policy rule in which, the behavior of policymakers is described by three Taylor-like policy rules depending on whether inflation is expected to be above, 
below or within the zone of discretion, which extends from $\delta$ percentage points above the intermediate inflation target to $\delta$ percentage points below. Interest rates respond to the expected output gap with a coefficient of $\rho_{y}$. The response of interest rates to inflation depends on whether inflation is expected to be outside the zone of discretion. If it is, the response of interest rates to inflation is $\rho_{O Z D}$; if it is not, the response is $\rho_{Z D}$. If $\rho_{O Z D} \neq \rho_{Z D}$, the response to inflation is not constant, so modeling monetary policy using a Taylor rule would not be appropriate. We would expect $\rho_{O Z D}>\rho_{Z D}$, so the response to inflation is stronger outside the zone of discretion. Aksoy et al (2005, pp 4-5) comment, "the marginal loss from a small output gap is of much greater importance to the Central Bank than the loss due to a small deviation of inflation from it's intermediate inflation target. Thus...\{in the zone of discretion\}...output stabilisation is the primary concern to the opportunistic policymaker. Larger deviations of inflation from the intermediate target, however, cause the policymaker to focus on inflation stabilisation". This implies $\rho_{\text {OZD }}>\rho_{y}$ and $\rho_{y}>\rho_{Z D}$. We also note that if $\rho_{Z D}=0$, then policymakers have a target range for inflation as they will seek to move inflation to the edges of the zone of discretion but will not seek to move inflation towards the intermediate inflation target once inflation is within the zone. If $\rho_{O Z D}=\rho_{Z D}$, then the model simplifies to

(5) $\quad i_{t}=i^{*}+\rho_{\pi} E_{t-1}\left(\pi_{t}-\pi^{I}{ }_{t}\right)+\rho_{y} E_{t-1} y_{t}$ 
while if we replace the intermediate inflation target in (1) with the inflation target, $\pi^{T}$, then the model further simplifies to the Taylor rule

$$
i_{t}=i^{*}+\rho_{\pi} E_{t-1}\left(\pi_{t}-\pi^{T}\right)+\rho_{y} E_{t-1} y_{t}
$$

Finally, we note that although these models assume interest rates respond to the current values of inflation and the output gap, it would not be difficult to amend the assumptions of the model to produce forward-looking versions of the behavioral relationships in (4)-(6).

\section{Testing the Opportunistic Approach to Monetary Policy}

In this section we assess the Opportunistic Approach using US data for the period 1983Q1-2004Q1. The sample corresponds to the chairmanships of Paul Volcker and Alan Greenspan, but excludes the period when the Federal Reserve targeted non-borrowed reserves, rather than interest rates ${ }^{3}$. The interest rate is measured by the effective federal funds rate and inflation is the annual proportional change in the CPI. We use real time output data from the Federal Reserve Bank of Philadelphia and measure the output gap as the deviation of this from a Hodrick-Prescott (1997) trend.

We begin by estimating simple linear Taylor rules. To allow for the high degree of interest rate smoothing that has been observed in previous studies, we assume

\footnotetext{
${ }^{3}$ Rudebusch (1998) points out that it is hard to estimate a stable US policy rule for the whole
} 


$$
i_{t}=\rho_{i} i_{t-1}+\left(1-\rho_{i}\right) \hat{i}_{t}
$$

where $\hat{i}$ is the desired interest rate, given by

$$
\hat{i}_{t}=i^{*}+\rho_{\pi}\left(E_{t-1} \pi_{t}-\pi^{T}\right)+\rho_{y} E_{t-1} y_{t}
$$

Combining (7) and (8) and invoking rational expectations, our empirical model is

$$
i_{t}=\rho_{i} i_{t-1}+\left(1-\rho_{i}\right)\left\{i^{*}+\rho_{\pi}\left(\pi_{t}-\pi^{T}\right)+\rho_{y} y_{t}\right\}+\varepsilon_{t}
$$

where $\varepsilon$ is an error term composed of the various expectational errors in (9). The restrictions embodied in (9) allow us to estimate the Taylor rule using GMM. Column (i) of Table 1 present estimates of this model. We estimate that $\rho_{\mathrm{i}}=0.92$ and that $\rho_{\pi}=1.76$, which are similar to that found in previous estimates (e.g. Judd and Rudebusch, 1998, Clarida et al, 2000). We estimate that $\rho_{y}=2.41$ which is higher than usual ${ }^{4}$. Column (ii) of Table 1 presents estimates of a forwardlooking version of this model, given by

\footnotetext{
postwar period.

${ }^{4}$ In a special issue of the North American Journal of Economics and Finance devoted to "Realtime data and monetary policy", Gerberding et al (2005) and Gerdesmeier and Roffia (2005) find that the use of real-time output data as opposed to ex-post output data increase the output effect in the Taylor rule for the Bundesbank and the EU area, respectively. A possible explanation is that the magnitude of the response using revised data could suffer from downward bias owing to the errors-in-variables problem.
} 


$$
i_{t}=\rho_{i} i_{t-1}+\left(1-\rho_{i}\right)\left\{i^{*}+\rho_{\pi} E_{t-1}\left(\pi_{t+1}-\pi^{T}\right)+\rho_{y} E_{t-1} y_{t}\right\}+\varepsilon_{t}
$$

Although the estimates are broadly similar (we estimate $\rho_{\mathrm{i}}=0.89, \rho_{\pi}=2.10$ and $\rho_{y}=2.00$ ), the forward-looking model fits the data better. However both models fail a parameter stability test.

We next estimate models that use the intermediate inflation target in place of the inflation target. To do this, we model the desired interest rate using

$$
\hat{i}_{t}=i^{*}+\rho_{\pi} E_{t-1}\left(\pi_{t}-\pi^{I}{ }_{t}\right)+\rho_{y} E_{t-1} y_{t}
$$

where we define the intermediate inflation target as

$$
\pi_{t}^{I}=\mu\left\{\frac{1}{n} \sum_{j=1}^{n} \pi_{t-j}\right\}+(1-\mu) \pi^{T}
$$

This model simply adds the intermediate inflation target to an otherwise standard Taylor rule to give an empirical counterpart to (5). We absorb the inflation target into the constant and do not seek to identify this at this stage. Column (iii) of Table 1 presents estimates of this model (where we use $n=4$ ), while column (iv) of Table 1 presents estimates of a forward-looking version of this model, given by

$$
i_{t}=\rho_{i} i_{t-1}+\left(1-\rho_{i}\right)\left\{i^{*}+\rho_{\pi} E_{t-1}\left(\pi_{t+1}-\pi_{t+1}^{I}\right)+\rho_{y} E_{t-1} y_{t}\right\}
$$


We note that both versions of the model produce broadly similar estimates but that the forward-looking model is again superior. In column (iv) we estimate that $\mu=0.59$ and find that the null hypothesis $\mathrm{H}_{0}: \mu=0$ is clearly rejected by the data. Comparing estimates in columns (iii) and (iv) with estimates in columns (i) and (ii), the inclusion of the intermediate inflation target improves the empirical fit of the model but has little effect on the estimates of other parameters. These results suggest that policymakers have an intermediate inflation target and thus provide support for this aspect of the Opportunistic Approach. However the estimates continue to fail parameter stability.

The second aspect of the Opportunistic Approach in which the behavior of policymakers differs according to whether inflation is expected to lie within the zone of discretion, implies that the models in Table 1 are misspecified, since they ignore the implied regime switching behavior of policymakers. We therefore test the estimated models in Table 1 for the presence of non-linearities. The last three rows of Table 1 report Hamilton's (2001) $\lambda$-test, and the $\lambda_{A}$ and $g$-tests proposed by Dahl and González-Rivera (2003). Under the null hypothesis of linearity, these are Lagrange multiplier test statistics following the $x^{2}$ distribution (a brief description of these tests is given in the Appendix of the paper) ${ }^{5}$. These tests are powerful in detecting non-linear smooth transition behavior (Dahl and González-Rivera, 2003). This is of particular interest as we shall use smooth transition specifications below. All three tests reject linearity.

\footnotetext{
${ }^{5}$ We run the tests using Gauss codes obtained from Hamilton's web page at: http://weber.ucsd.edu/ jhamilto/software.htm\#other. To account for the rather small sample, we report bootstrapped $p$-values of the three tests based on 1000 re-samples.
} 
Having rejected linearity, we next consider the model

$$
\left\{\begin{array}{c}
i_{t}=\rho_{i} i_{t-1}+\left(1-\rho_{i}\right)\left\{i^{*}+\rho_{Z D} E_{t-1}\left(\pi_{t}-\pi^{I}{ }_{t}\right)+\rho_{y} E_{t-1} y_{t}\right\} \\
\text { if }\left\{-\delta \leq E_{t-1}\left(\pi_{t}-\pi^{I}{ }_{t}\right) \leq \delta\right\} \\
i_{t}=\rho_{i} i_{t-1}+\left(1-\rho_{i}\right)\left\{i^{*}+\rho_{O Z D} E_{t-1}\left(\pi_{t}-\pi^{I}{ }_{t}+\delta\right)+\rho_{y} E_{t-1} y_{t}\right\} \\
\text { if }\left\{-\delta>E_{t-1}\left(\pi_{t}-\pi^{I}{ }_{t}\right)\right\} \\
i_{t}=\rho_{i} i_{t-1}+\left(1-\rho_{i}\right)\left\{i^{*}+\rho_{O Z D} E_{t-1}\left(\pi_{t}-\pi^{I}{ }_{t}-\delta\right)+\rho_{y} E_{t-1} y_{t}\right\} \\
\text { if }\left\{\delta<E_{t-1}\left(\pi_{t}-\pi^{I}{ }_{t}\right)\right\}
\end{array}\right\}
$$

This is the model of Orphanides and Wilcox (2002) in (4) adapted to incorporate interest rate smoothing. Preliminary estimates consistently found no response to inflation within the zone of discretion; setting $\rho_{\mathrm{ZD}}=0$ improved the efficiency of the estimates and so this is imposed in the estimates of the model reported in column (i) of Table 2. The results are mixed. The estimates of $\rho_{i}, \rho_{y}$ and $\mu$ are similar to those reported in Table 1; the latter confirming the support for the intermediate inflation target that was reported in Table 1. The response to inflation outside the zone of discretion is very large, $\rho_{O Z D}=9.24$, while there is no response to inflation within the zone. We estimate that $\delta=1.01$, so the zone of discretion extends from 1 percentage point above the intermediate inflation target to 1 percentage point below. The implied width of 2 percentage points for the zone of discretion seems reasonable. We cannot reject the hypotheses $\rho_{z D}<\rho_{y}$ and $\rho_{\mathrm{OzD}}>\rho_{\mathrm{y}}$, so the evidence supports a key prediction of the Opportunistic Approach, that policymakers respond more strongly to output inside the zone of 
discretion but more strongly to inflation outside the zone. The estimates pass a parameter stability test, in contrast to the estimates in table 1). The standard error is lower than the Taylor rule in column (iii) of Table 1 but higher than the forward-looking Taylor rule of column (iv) of Table 1. This suggests that a forward-looking version of this model might be preferable. Column (ii) of Table 2 presents estimates of such a model, given by

$$
\left\{\begin{array}{c}
i_{t}=\rho_{i} i_{t-1}+\left(1-\rho_{i}\right)\left\{i^{*}+\rho_{Z D} E_{t-1}\left(\pi_{t+1}-\pi^{I}{ }_{t+1}\right)+\rho_{y} E_{t-1} y_{t}\right\} \\
\text { if }\left\{-\delta \leq E_{t-1}\left(\pi_{t+1}-\pi^{I}{ }_{t+1}\right) \leq \delta\right\} \\
i_{t}=\rho_{i} i_{t-1}+\left(1-\rho_{i}\right)\left\{i^{*}+\rho_{\text {OZD }} E_{t-1}\left(\pi_{t+1}-\pi^{I}{ }_{t+1}+\delta\right)+\rho_{y} E_{t-1} y_{t}\right\} \\
\text { if }\left\{-\delta>E_{t-1}\left(\pi_{t+1}-\pi^{I}{ }_{t+1}\right)\right\} \\
i_{t}=\rho_{i} i_{t-1}+\left(1-\rho_{i}\right)\left\{i^{*}+\rho_{O Z D} E_{t-1}\left(\pi_{t+1}-\pi^{I}{ }_{t+1}-\delta\right)+\rho_{y} E_{t-1} y_{t}\right\} \\
\text { if }\left\{\delta<E_{t-1}\left(\pi_{t+1}-\pi^{I}{ }_{t+1}\right)\right\}
\end{array}\right\}
$$

This model has a lower standard error than the models in Table 1 and has a lower response to inflation outside the zone of discretion.

\section{Refinements and Robustness of the Opportunistic Approach}

The estimates in the previous section suggest that the Opportunistic Approach to monetary policy has empirical support, especially when modified to allow for a forward-looking response to inflation. In this section we consider refinements of this approach, investigating whether the empirical fit of the model can be improved. Our first refinement allows a smoother transition between regimes. We consider the model 


$$
\left\{\begin{array}{c}
i_{t}=\rho_{i} i_{t-1}+\left(1-\rho_{i}\right)\left\{i^{*}+\rho_{Z D} E_{t-1}\left(\pi_{t+1}-\pi^{I}{ }_{t+1}\right)+\rho_{y} E_{t-1} y_{t}\right\} \\
\operatorname{pr}\left\{-\delta \leq E_{t-1}\left(\pi_{t+1}-\pi^{I}{ }_{t+1}\right) \leq \delta\right\} \\
i_{t}=\rho_{i} i_{t-1}+\left(1-\rho_{i}\right)\left\{i^{*}+\rho_{O Z D} E_{t-1}\left(\pi_{t+1}-\pi^{I}{ }_{t+1}+\delta\right)+\rho_{y} E_{t-1} y_{t}\right\} \\
\operatorname{pr}\left\{-\delta>E_{t-1}\left(\pi_{t+1}-\pi^{I}{ }_{t+1}\right)\right\} \\
i_{t}=\rho_{i} i_{t-1}+\left(1-\rho_{i}\right)\left\{i^{*}+\rho_{O Z D} E_{t-1}\left(\pi_{t+1}-\pi^{I}{ }_{t+1}-\delta\right)+\rho_{y} E_{t-1} y_{t}\right\} \\
\operatorname{pr}\left\{\delta<E_{t-1}\left(\pi_{t+1}-\pi^{I}{ }_{t+1}\right)\right\}
\end{array}\right\}
$$

Equation (16) differs from (15) in that the regimes are weighted by the probability of being in each regime. Equation (16) is a smooth transtion model, in which the movement between regimes is less abrupt than in (15). We model the probabilities in (16) using the logistic functions (see e.g. van Dijk et al, 2002)

$$
\operatorname{pr}\left\{-\delta>E_{t-1}\left(\pi_{t+1}-\pi^{I}{ }_{t+1}\right)\right\}=1-\frac{1}{1+e^{-\gamma E_{t-1}\left(\pi_{t+1}-\pi_{t+1}^{I}+\delta\right) / \sigma_{E_{t-1}\left(\pi_{t+1}-\pi_{t+1}^{I}\right)}}}
$$

and

$$
\operatorname{pr}\left\{\delta<E_{t-1}\left(\pi_{t+1}-\pi^{I}{ }_{t+1}\right)\right\}=\frac{1}{1+e^{-\gamma E_{t-1}\left(\pi_{t+1}-\pi_{t+1}^{I}-\delta\right) / \sigma_{E_{t-1}\left(\pi_{t+1}-\pi_{t+1}^{I}\right)}}}
$$

In (17a) and (17b), the smoothness parameter $\gamma>0$ determines the smoothness of the transition regimes. We follow Granger and Teräsvirta (1993) and Teräsvirta (1994) in making $\gamma$ dimension-free by dividing it by the standard deviation of $E_{t-1}\left(\pi_{t+1}-\pi_{t+1}^{I}\right)$.

Preliminary estimates again found no response to inflation within the zone of discretion and that setting $\rho_{\mathrm{ZD}}=0$ improved the efficiency of the estimates; this 
restriction is imposed in the estimates of the model reported in column (iii) of Table 2. The estimates are similar to those in column (ii) of Table 2 but the standard error is lower.

Our second refinement develops the smooth transition model in (16) by simplifying the model. The model considered so far assumes that interest rates respond to $E_{t-1}\left(\pi_{t+1}-\pi_{t+1}^{I}+\delta\right)$ when the economy is below the zone of discretion, and to $E_{t-1}\left(\pi_{t+1}-\pi^{I}{ }_{t+1}-\delta\right)$ when it is above. If we assume instead that interest rates respond to $E_{t-1}\left(\pi_{t+1}-\pi^{I}{ }_{t+1}\right)$, then we can simplify the model to

$$
\begin{aligned}
& i_{t}=\rho_{i} i_{t-1}+\left(1-\rho_{i}\right)\left\{i^{*}+\rho_{y} E_{t-1} y_{t}+\theta_{t} \rho_{Z D} E_{t-1}\left(\pi_{t+1}-\pi^{I}{ }_{t+1}\right)\right. \\
& \left.+\left(1-\theta_{t}\right) \rho_{O Z D} E_{t-1}\left(\pi_{t+1}-\pi^{I}{ }_{t+1}\right)\right\}+\varepsilon_{t}
\end{aligned}
$$

where $\theta_{t}=\operatorname{pr}\left\{-\delta \leq E_{t-1}\left(\pi_{t+1}-\pi_{t+1}^{I}\right) \leq \delta\right\}$ is the probability that the economy is within the zone of discretion. Equation (18) is similar to the modified Taylor rule in (13) except that the response to inflation is contingent on whether inflation is within the zone of discretion. We model the probability of being within the zone using the quadratic logistic function (see e.g. van Dijk et al, 2002)

$$
\text { (19) } \theta_{t}=\operatorname{pr}\left\{-\delta \leq E_{t-1}\left(\pi_{t+1}-\pi_{t+1}^{I}\right) \leq \delta\right\}=1-\frac{1}{1+e^{-\gamma\left[E_{t-1}\left(\pi_{t+1}-\pi_{t+1}^{I}+\delta\right)\left[E_{t-1}\left(\pi_{t+1}-\pi_{t+1}^{I}-\delta\right)\right] / \sigma_{E_{t-1}\left(\pi_{t+1}-\pi_{t+1}^{I}\right)}\right.}}
$$

As before, preliminary estimates found no response to inflation within the zone of discretion and we again imposed $\rho_{\mathrm{ZD}}=0$, to improve the efficiency of our 
estimates, which are reported in column (iv) of Table 2. The estimates of the model are similar to those before, except that the response to inflation is lower and arguably more plausible: $\rho_{\mathrm{OzD}}=3.59$. The standard error is substantially lower than those of other models. This simplified version of the model fits the data better than other models and continues to provide support for the Opportunistic Approach.

Our final refinement relaxes the assumption that the zone of discretion is symmetric around the intermediate inflation target. To do this, we use equation (18) and express the probability of being in the zone of discretion as

$$
\text { (20) } \theta_{t}=\operatorname{pr}\left\{-\delta^{L} \leq E_{t-1}\left(\pi_{t+1}-\pi^{I}{ }_{t+1}\right) \leq \delta^{U}\right\}=1-\frac{1}{1+e^{-\gamma\left[E_{t-1}\left(\pi_{t+1}-\pi_{t+1}^{I}+\delta^{L}\right)\right]\left[E_{t-1}\left(\pi_{t+1}-\pi_{t+1}^{I}-\delta^{U}\right)\right] / \sigma_{E_{t-1}\left(\pi_{t+1}-\pi_{t+1}^{I}\right)}^{2}}}
$$

In (20) the zone of discretion extends from $\delta^{U}$ percentage points above the intermediate target to $\delta^{L}$ percentage points below it. Estimates of this model are presented in column (v) of Table 2. These are similar to those of the model in column (iv) of Table 2. We estimate that $\delta^{U}=1.03$ while $\delta^{L}=1.06$. We cannot reject the restriction that $\delta^{U}=\delta^{L}$ and so conclude that the zone of discretion is symmetric. $^{6}$

\footnotetext{
${ }^{6}$ For the smoothness parameter, $\gamma$, we run a grid search over the $[0.5,300]$ range of numerical values. For columns (iii)-(v) of Table 2, we selected $\gamma=10$. Although we would have liked to estimate $\gamma$ as a free parameter, this proved problematic; accurate estimation of $\gamma$ requires many observations in the immediate neighbourhood of the regime boundaries. Furthermore, large
} 


\section{Robustness analysis}

We investigated the robustness of our results by assuming $n=1$ in equation (12) for the intermediate inflation target and by using alternative measures of the output gap. These were obtained by applying the HodrickPrescott filter to the final real GDP series as a measure of potential output and by taking the difference between the logarithm of final real GDP and the logarithm of the Congressional Budget Office (CBO) measure of potential GDP. Further, we measured expected inflation by the annual one-period ahead mean forecasts obtained by the Survey of Professional Forecasters (SPF) ${ }^{7}$. Columns (i) to (iv) of Table 3 report the alternative estimates of the model in (18) using the quadratic logistic function (20) which allows for an asymmetric zone of discretion. The estimates are similar to those of column (iv) in Table 2 although with a much smaller response to the output gap when final output data are used; the output response is insignificant when the CBO measure of potential output is used ${ }^{8}$. These alternative estimates provide empirical support for the Opportunistic Approach and confirm our finding that zone of discretion is symmetric.

The Hodrick-Prescott filter is a two-sided symmetric filter in the sense that it uses data on past and future output symmetrically to decompose each output observation. The HP filter is optimal (in the expected squared error sense) for the midpoint of the output series but not for the endpoints of the series where it

changes in $\gamma$ have a small impact on the shape of the functions (17a), (17b), (19) and (20), which implies that the $\gamma$ estimate does not need be precise (van Dijk et al, 2002).

${ }^{7}$ These were obtained from the web site of the Federal Reserve Bank of Philadelphia at: http://www.phil.frb.org/econ/spf/index.html.

${ }^{8}$ This points to a downward bias owing to the errors-in-variables problem when revised data are used (see footnote 4). 
becomes increasingly one-sided; this affects the efficiency properties of the filter. To correct this, Mise et al $(2005 a, b)$ suggest the construction of the output gap by applying the Hodrick-Prescot filter to a forecast-augmented output series. Garratt et al (2005) generate these forecasts using (i) a univariate model of the real-time output and (ii) a bivariate vector autoregression which estimates jointly real-time output data and its revisions. Garratt et al (2005) argue that the joint modeling of real-time output and its revisions avoids the problem of overstating the revision effects in the published output data if these revision effects have been anticipated. Columns (v) and (vi) of Table 3 present estimates using these alternative measures of the Hodrick-Prescott output series. These estimates are very similar to those of our preferred model in column (iv) of Table 2, so allowing for possible weaknesses in our measure of the output gap makes little difference to our estimates.

\section{Implications of the Opportunistic Approach}

The Opportunistic Approach provides a richer account of monetary policy than the familiar Taylor rule. In particular, the response to inflation varies over time, in contrast to the constant response implied by the Taylor rule. Although the average response to inflation across our sample is 1.89 , which, as we would expect, is similar to the estimates of the Taylor rules in columns (i) to (iv) of Table 1 , the response to inflation implied by the Taylor rule is highly misleading. In practice, interest rates were either far more responsive to inflation or else did not respond at all. 
Figure 1 illustrates the difference between the opportunistic model and the Taylor rule model by depicting the deviation of interest rates from equilibrium as a function of the inflation gap. While the response implied by the Taylor rule is linear, the response of the opportunistic approach is nonlinear. Interest rates do not respond to inflation within the zone of opportunism; but as the edge of the zone is approached, a response to inflation emerges rapidly, quickly over-taking the response implied by the Taylor rule. In this, there are clear similarities with the inflation zone targeting model of Orphanides and Weiland (2000). Figure 2 further illustrates the difference between the models by plotting the marginal response of interest rates to inflation $\left(\frac{d i_{t}}{d E_{t-1}\left(\pi_{t+1}-\pi^{I}{ }_{t+1}\right)}\right)$ implied by our estimates for each data point. While the Taylor rule implies a constant marginal response, the opportunistic model implies a marginal response of zero within the zone of opportunism but which rapidly rises to a level greater than that of the Taylor rule as inflation approaches and crosses the boundaries of the zone.

The implications of the Opportunistic Approach for US monetary policy over the past 25 years are illustrated in Figure 3a), where we plot expected inflation, the intermediate target, the zone of discretion and the long-run timevarying impact of inflation on interest rates. The graph assumes an inflation target of 2\%; this reflects the original assumption of Taylor (1993) which appears to have become the consensus view on the desired inflation rate. There are frequent changes in the intermediate inflation target, which fluctuates between highs of 4\% in 1983 and 1991 and lows of just over 2\% in 1986 and late 2001. Expected inflation remained within the zone of discretion for most of the sample 
period, but exceeded the upper bound in 1984, 1988-1990 and came close to doing so in 2000 and 2002. Expected inflation came very close to the lower bound in 1987 and briefly fell below the bound in late 2001 .

Fluctuations in expected inflation around the intermediate target are mirrored in the estimated time-varying response of inflation to the expected inflation rate. This is calculated (using the estimates in column (iv) of Table 2) as:

(21) $\rho_{\pi t}=\theta_{t} \rho_{Z D}+\left(1-\theta_{t}\right) \rho_{O Z D}$

As Figure 3b) shows, the weight on inflation effect reaches 3.59 when expected inflation approaches or exceeds the bounds of the zone of discretion. This happens in 1984, in 1987-1990, and in late 2001. On the other hand, the impact of inflation is much less when expected inflation moves further within the zone of discretion, and drops to zero when expected inflation is close to the intermediate target in late 1986, from late 1991 up to 1998, in early 2001 and after 2003. 


\section{Conclusions}

The Opportunistic Approach to Monetary Policy is an influential but untested model of optimal monetary policy. We provide the first tests of the model, using US data from 1983Q1-2004Q1.

Our results support the Opportunistic Approach. We find that policymakers respond to the gap between inflation and an intermediate target that reflects the recent history of inflation. We find that there is no response of interest rates to inflation when inflation is within $1 \%$ of the intermediate target but a strong response when inflation is further from the intermediate target.

These estimates are only a first attempt to test the Opportunistic Approach. But they do show that behavior of policymakers is more subtle and complex than assumed in the familiar Taylor rule. Further research around these issues may well prove fruitful. 


\section{References}

Aksoy, Y., A. Orphanides, D. Small, V. Weiland and D. Wilcox (2005). A quantitative exploration of the Opportunistic Approach to disinflation, forthcoming, Journal of Monetary Economics.

Bernanke, B. (2003). Constrained discretion and monetary policy, speech at New York University.

Bernanke, B. and F. Mishkin (1997). Inflation targeting: a new framework for monetary policy?, Journal of Economic Perspectives, 11, pp 97-116.

Clarida, R.J., M. Gali and M. Gertler (2000). Monetary policy rules and macroeconomic stability: evidence and some theory, Quarterly Journal of Economics, 115, pp 147-180.

Dahl, C.M. and G. González-Rivera (2003). Testing for neglected nonlinearity in regression models based on the theory of random fields, Journal of Econometrics, 114, pp 141-164.

Eitrheim, $\varnothing$. and T. Teräsvirta (1996). Testing the adequacy of smooth transition autoregressive models, Journal of Econometrics, 74, pp 59-75.

Garratt, A., K. Lee, E. Mise and K. Shields (2005). Real time representations of the output gap. Paper presented at the CIRANO and Bank of Canada's Workshop on 'Macroeconomic Forecasting, Analysis and Policy with Data Revisions', 14 October 2005.

Gerberding, C., Seitz F. and A. Worms (2005). How the Bundesbank really conducted monetary policy, North American Journal of Economics and Finance, 16, pp 277-292. 
Gerdesmeier, D. and B. Roffia (2005). The relevance of real-time data in estimating reaction functions for the euro area, North American Journal of Economics and Finance, 16, pp 293-307.

Granger, C.W.J. and T. Teräsvirta (1993). Modelling Nonlinear Economic Relationships. Oxford: Oxford University Press.

Hamilton, J.D. (2001). A parametric approach to flexible nonlinear inference, Econometrica, 69, pp 537-573.

Hansen, L.P. (1982). Large sample properties of generalized method of moments estimators, Econometrica, 82, pp 1029-1054.

Hodrick, R.J. and E.C. Prescott (1997). Postwar U.S. business cycles: An empirical investigation, Journal of Money, Credit, and Banking, 29, pp 1-16.

Judd, J. and G. Rudebusch (1998). Taylor's rule and the Fed: 1970-97, Federal Reserve Bank of San Francisco Economic Review, 3, pp 3-16.

Lin, C-F.J. and T. Teräsvirta (1994). Testing the constancy of regression parameters against continuous structural change, Journal of Econometrics, 62, pp 211-228.

Minford, P. and N. Srinivasan (2006). Opportunistic Monetary Policy: an Alternative Rationalization, Journal of Economics and Business (to appear).

Mise, E., T-H. Kim and P. Newbold (2005a). On the sub-optimality of the HodrickPrescott filter, Journal of Macroeconomics, 27, pp 53-67.

Mise, E., T-H. Kim and P. Newbold (2005b). Correction of the distortionary endeffect of the Hodrick-Prescott filter: Application", mimeo, downloadable from: 
http://www.le.ac.uk/economics/staff/em92.html

Orphanides, A. and V. Wieland (2000). Inflation zone targeting, European Economic Review, 44, pp 1351-1387.

Orphanides, A. and D. Wilcox (2002). The Opportunistic Approach to Disinflation, International Finance, 5, pp 47-71.

Rudebusch, G. (1998). Do measures of monetary policy in a VAR make sense?, International Economic Review, 39, pp 907-931.

Svensson, L.E.O (2003). What Is wrong with Taylor rules? Using judgment in monetary policy through targeting rules, Journal of Economic Literature, 41, 426477.

Taylor, J. (1993). Discretion versus policy rules in practice, Carnegie-Rochester Conference Series on Public Policy, 39, pp 195-214.

Teräsvirta, T. (1994). Specification, estimation, and evaluation of smooth transition autoregressive models, Journal of the American Statistical Association, 89, pp 208-218.

van Dijk, D., T. Teräsvirta, and P.H. Franses (2002). Smooth transition autoregressive models - a survey of recent developments, Econometric Reviews, 21, pp 1-47. 


\section{Appendix: Non-linearity tests}

Hamilton's (2001) $\lambda$-test and the $\lambda_{A}$ and $g$-tests proposed by Dahl and GonzálezRivera (2003) draw on the assumption that the conditional mean function of the dependent variable is stochastic and therefore unobservable or unknown to the econometrician. The testing procedure is based on the regression

$y_{t}=\beta_{0}+\boldsymbol{x}_{t}^{\prime} \boldsymbol{\beta}_{1}+\lambda m\left(\boldsymbol{g} \otimes \boldsymbol{x}_{\boldsymbol{t}}\right)+$ error

The conditional mean of the dependent variable is a function of a linear and a non-linear component. The linear component is given by $\boldsymbol{x}_{t}^{\prime} \boldsymbol{\beta}_{1}$ where $\boldsymbol{x}_{\boldsymbol{t}}$ is a $k$ dimensional vector of the explanatory variables (excluding the intercept term). The non-linear component is given by $\lambda m\left(\boldsymbol{g} \otimes \boldsymbol{X}_{\boldsymbol{t}}\right)$, where $m($.$) is a k$-dimensional system of random variables depending on the distance amongst the elements of the $\boldsymbol{x}_{\boldsymbol{t}}$ vector, and $\otimes$ denotes element-by-element multiplication. The scalar $\lambda$ proxies the contribution of the non-linear part to the conditional mean, whereas $\mathbf{g}$ is a $k$-dimensional vector capturing the curvature of the conditional mean. The null hypothesis of linearity involves testing the null hypothesis $\mathrm{H}_{0}: \lambda^{2}=0$ for the $\lambda$ and $\lambda_{A}$ tests and the null hypothesis $\mathrm{H}_{0}: \boldsymbol{g}=\mathbf{0}_{k}$ for the $\boldsymbol{g}$-test. These are Lagrange multiplier test statistics following the $x^{2}$ distribution (for more technical details see Hamilton, 2001, and Dahl and González-Rivera, 2003). Dahl and González-Rivera (2003) report simulation evidence according to which (i) their tests are more powerful than Hamilton's original test when the dimensionality of 
the model (in terms of parameters to be estimated) increases, and (ii) their tests are powerful in detecting smooth transition specifications. The latter is important as the opportunistic models we consider in this paper are smooth transition-type models. 
Table 1

Estimates of Taylor rules and augmented Taylor rules

GMM estimates on US data, 1983Q1-2004Q1

\begin{tabular}{|l|l|l|l|l|}
\hline & \multicolumn{1}{|c|}{ (i) } & \multicolumn{1}{c|}{ (ii) } & \multicolumn{1}{c|}{ (iii) } & \multicolumn{1}{c|}{ (iv) } \\
\hline & \multicolumn{1}{c|}{} & & & \\
\hline$\rho_{\mathrm{i}}$ & $0.92(0.03)$ & $0.89(0.03)$ & $0.93(0.02)$ & $0.89(0.02)$ \\
\hline$\rho_{\pi}$ & $1.76(0.63)$ & $2.10(0.46)$ & $1.81(0.56)$ & $2.16(0.55)$ \\
\hline$\rho_{\mathrm{y}}$ & $2.41(0.89)$ & $2.00(0.65)$ & $2.39(0.98)$ & $2.18(0.79)$ \\
\hline$\mu$ & & & $0.64(0.24)$ & $0.59(0.27)$ \\
\hline & & & & \\
\hline s.e. & 0.490 & 0.473 & 0.481 & 0.461 \\
\hline F-stability (p-value) & 0.00 & 0.00 & 0.00 & 0.00 \\
\hline J-stat (p-value) & 0.56 & 0.57 & 0.56 & 0.56 \\
\hline$\lambda$-test (p-value) & 0.02 & 0.02 & 0.04 & 0.03 \\
\hline$\lambda_{A}$-test (p-value) & 0.01 & 0.02 & 0.01 & 0.03 \\
\hline$g$-test (p-value) & 0.00 & 0.01 & 0.02 & 0.00 \\
\hline
\end{tabular}

Notes: Numbers in parentheses are the standard errors of the estimates. s.e. is the regression standard error. J stat is a chi-square test of the model's overidentifying restrictions (Hansen, 1982). The instruments are a constant and six lags of the variables in the estimated rule. Parameter stability is an F test of parameter stability (see Lin and Teräsvirta, 1994, and Eitrheim and Teräsvirta, 1996). The table also reports bootstrapped $p$-values of the $\lambda, \lambda_{A}$, and $g$ tests based on 1000 re-samples. 
Table 2

Estimates of the Opportunistic Approach

GMM estimates on US data, 1983Q1-2004Q1

\begin{tabular}{|l|l|l|l|l|l|}
\hline & \multicolumn{1}{|c|}{ (i) } & \multicolumn{1}{c|}{ (ii) } & \multicolumn{1}{c|}{ (iii) } & \multicolumn{1}{c|}{ (iv) } & \multicolumn{1}{c|}{ (v) } \\
\hline & & & & & \\
\hline$\rho_{\mathrm{i}}$ & $0.89(0.07)$ & $0.92(0.11)$ & $0.92(0.02)$ & $0.92(0.02)$ & $0.91(0.02)$ \\
\hline$\rho_{\mathrm{ZD}}$ & & & & & \\
\hline$\rho_{\mathrm{OZD}}$ & $9.24(4.89)$ & $6.01(1.49)$ & $6.40(1.95)$ & $3.59(0.73)$ & $3.60(0.74)$ \\
\hline$\rho_{y}$ & $2.56(2.11)$ & $2.47(0.95)$ & $2.37(0.74)$ & $2.62(0.41)$ & $2.60(0.41)$ \\
\hline$\mu$ & $0.62(0.10)$ & $0.62(0.11)$ & $0.63(0.09)$ & $0.63(0.09)$ & $0.63(0.14)$ \\
\hline$\delta$ & $1.01(0.23)$ & $1.10(0.24)$ & $1.05(0.08)$ & $1.05(0.08)$ & \\
\hline$\delta^{L}$ & & & & & $1.06(0.19)$ \\
\hline$\delta^{U}$ & & & & & $1.03(0.10)$ \\
\hline s.e. & 0.467 & 0.460 & 0.456 & 0.419 & 0.419 \\
\hline $\begin{array}{l}\text { F-stability } \\
(p-v a l u e)\end{array}$ & 0.11 & 0.11 & 0.10 & 0.11 & 0.11 \\
\hline $\begin{array}{l}\text { J-stat } \\
(p-v a l u e)\end{array}$ & 0.32 & 0.34 & 0.35 & 0.32 & 0.35 \\
\hline & & & & & \\
\hline
\end{tabular}

Notes: Numbers in parentheses are the standard errors of the estimates. s.e. is the regression standard error. J stat is a chi-square test of the model's overidentifying restrictions (Hansen, 1982). The instruments are a constant and six lags of the variables in the estimated rule. Parameter stability is an F test of parameter stability (see Lin and Teräsvirta, 1994, and Eitrheim and Teräsvirta, 1996). 


\section{Table 3}

Estimates of the Opportunistic Approach based on alternative measures

GMM estimates on US data, 1983Q1-2004Q1

\begin{tabular}{|l|l|l|l|l|l|l|}
\hline & $\begin{array}{c}\text { (i) } \\
\text { Estimates }\end{array}$ & \multicolumn{1}{|c|}{$\begin{array}{c}\text { (ii) } \\
\text { Final output } \\
\text { data }\end{array}$} & $\begin{array}{c}\text { (iii) } \\
\text { CBO } \\
\text { measure of } \\
\text { output }\end{array}$ & $\begin{array}{c}\text { (iv) } \\
\text { SPF } \\
\text { measure of } \\
\text { inflation }\end{array}$ & $\begin{array}{c}\text { (v) } \\
\text { Univariate } \\
\text { HP forecast } \\
\text { augmented } \\
\text { output }\end{array}$ & $\begin{array}{c}\text { (vi) } \\
\text { Bivariate } \\
\text { HP forecast } \\
\text { augmented } \\
\text { output }\end{array}$ \\
\hline$\rho_{\mathrm{i}}$ & $0.93(0.03)$ & $0.92(0.03)$ & $0.94(0.02)$ & $0.93(0.03)$ & $0.94(0.02)$ & $0.93(0.03)$ \\
\hline$\rho_{\mathrm{ZD}}$ & & & & & & \\
\hline$\rho_{\mathrm{OZD}}$ & $3.33(0.81)$ & $3.07(1.07)$ & $3.73(1.05)$ & $4.28(1.31)$ & $3.57(1.20)$ & $3.31(0.94)$ \\
\hline$\rho_{\mathrm{y}}$ & $2.79(0.42)$ & $1.25(0.61)$ & $0.49(0.41)$ & $1.94(0.79)$ & $2.51(0.81)$ & $1.81(0.71)$ \\
\hline$\mu$ & $0.65(0.06)$ & $0.64(0.10)$ & $0.71(0.03)$ & $0.66(0.11)$ & $0.64(0.09)$ & $0.63(0.08)$ \\
\hline$\delta^{L}$ & $1.06(0.02)$ & $0.86(0.14)$ & $1.05(0.01)$ & $0.96(0.18)$ & $1.02(0.02)$ & $0.97(0.01)$ \\
\hline$\delta^{U}$ & $1.05(0.01)$ & $0.88(0.10)$ & $1.03(0.01)$ & $0.99(0.10)$ & $1.01(0.01)$ & $0.96(0.01)$ \\
\hline
\end{tabular}

Notes: Numbers in parentheses are the standard errors of the estimates. 
Figure 1: Deviations of interest rates from equilibrium as a function of the inflation gap

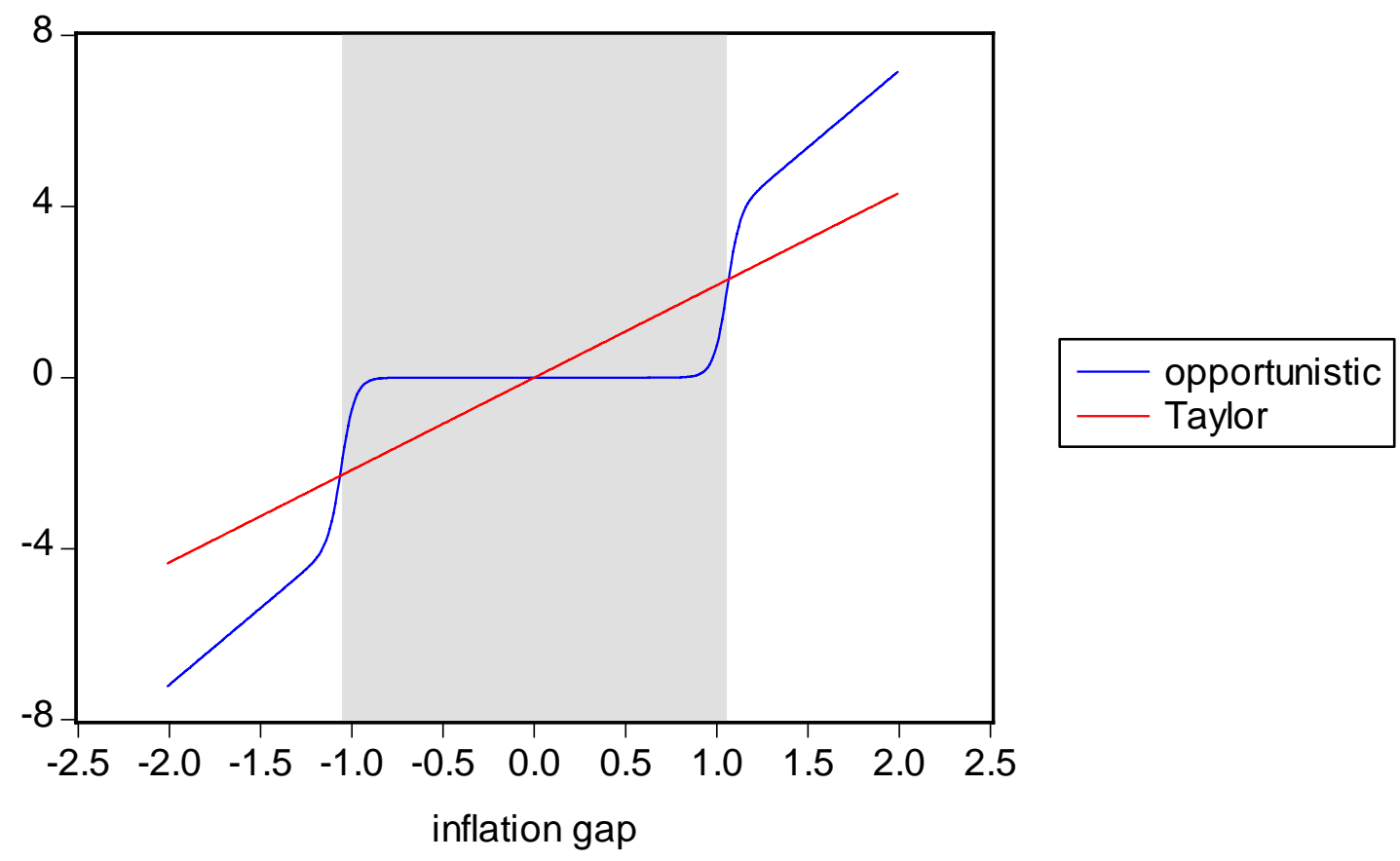

Note: The figure plots the deviation of interest rates from equilibrium due to the inflation gap implied by the estimates in column (iv) of Table 1 and column (iv) of Table 2. The curves are given by $\rho_{\pi} \pi g a p$ in the case of the Taylor rule and by $\left[\theta_{t} \rho_{Z D}+\left(1-\theta_{t}\right) \rho_{O Z D}\right] \pi g a p$ for the opportunistic model, where $\pi g a p$ is the inflation gap. The shaded area represents the zone of discretion. The lower bound is $\pi$ gap $-\delta$ and the upper bound is $\pi g a p+\delta$ using the estimates in column (iv) of Table 2. 
Figure 2: The marginal response of interest rates to changes in inflation

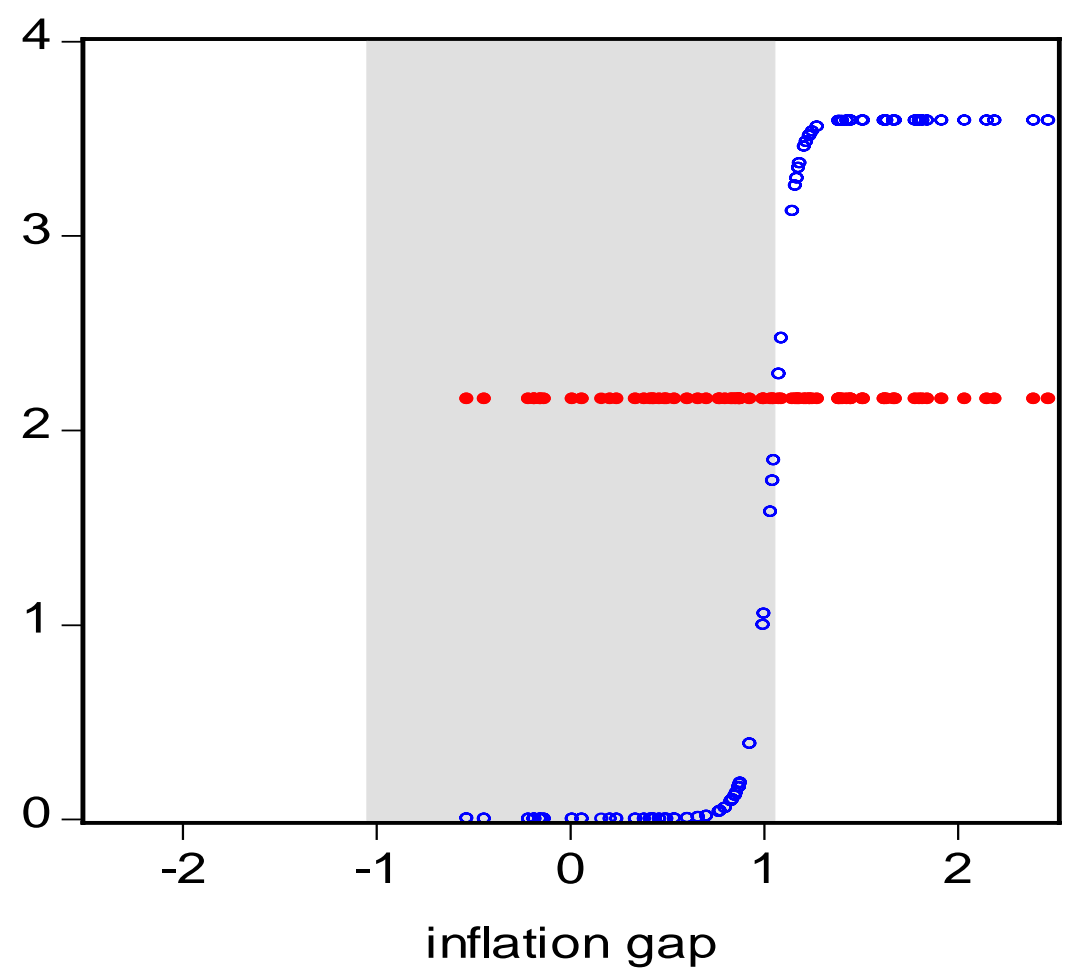

- nonlinear response

- linear response

Note: The shaded area represents the zone of discretion. The lower bound is $E_{t-1}\left(\pi_{t+1}-\pi_{t+1}^{I}\right)-\delta$ and the upper bound is $E_{t-1}\left(\pi_{t+1}-\pi_{t+1}^{I}\right)+\delta$ using the estimates in column (iv) of Table 2. The nonlinear inflation effect is equal to $\rho_{\pi t}=\theta_{t} \rho_{Z D}+\left(1-\theta_{t}\right) \rho_{O Z D}$, whereas the linear inflation effect is equal to $\rho_{\pi}$ using $\rho_{\pi}=2.16$ from column (iv) of Table 1 . To facilitate comparison in the same graph, the horizontal axis of Figure 2 uses $\mu=0.63$ to construct the inflation gap. 
Figure 3: The time-varying impact of inflation on the US interest rate using $\pi^{T}=2$

(a) Expected inflation, intermediate target and zone of discretion

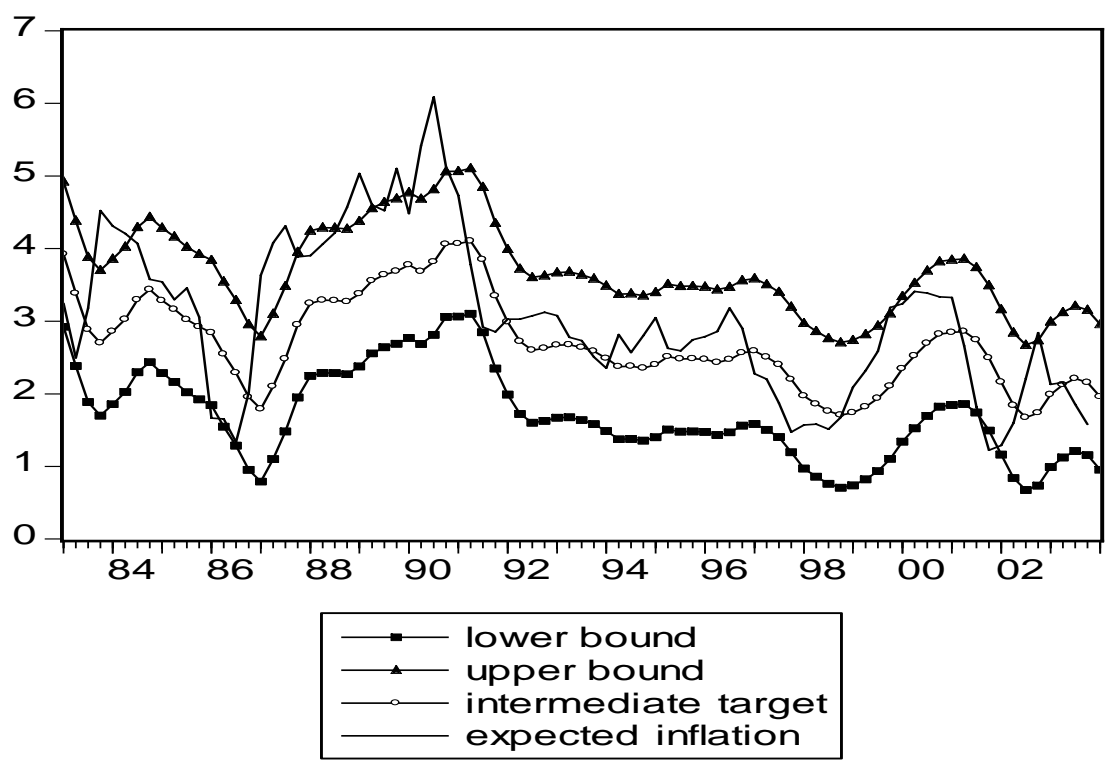

(b) Time-varying inflation effect and the US interest rate

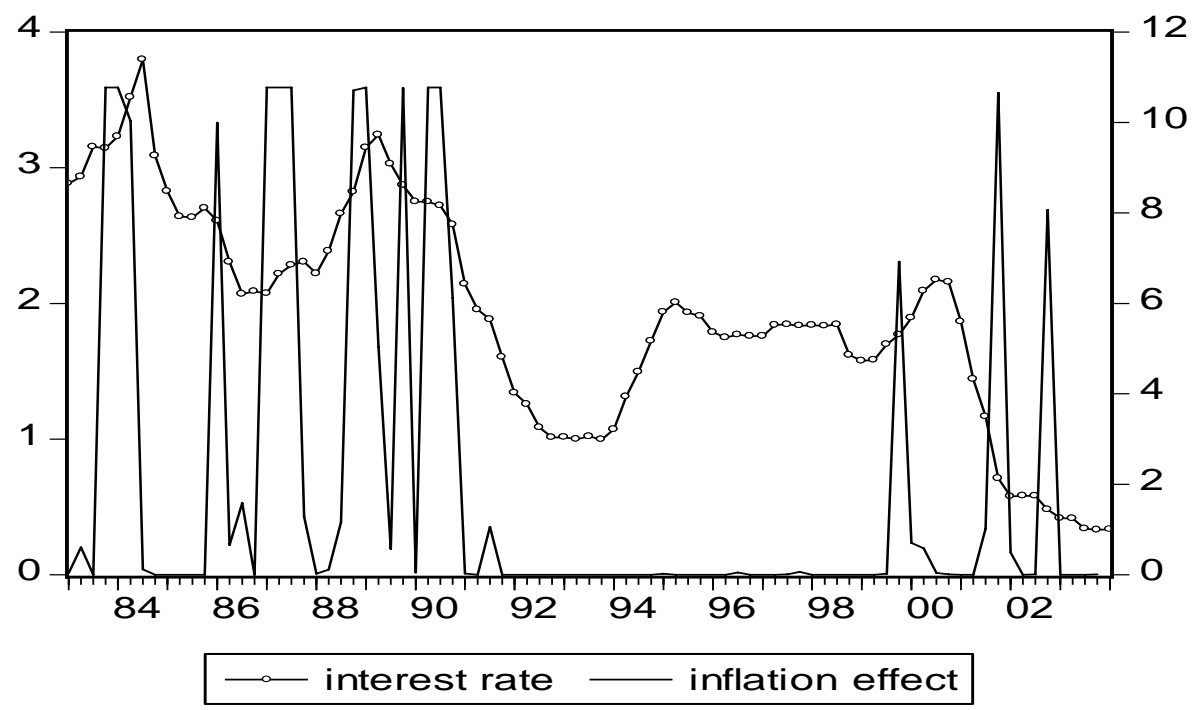

Note: The figure plots expected inflation $\left(E_{t-1} \pi_{t+1}\right)$ together with the intermediate target $E_{t-1} \pi_{t+1}^{I}=\mu\left\{\frac{1}{n} \sum_{j=1}^{n} E_{t-1} \pi_{t+1-j}\right\}+(1-\mu) \pi^{T}$, the lower bound $E_{t-1} \pi_{t+1}^{I}-\delta$ and the upper bound $E_{t-1} \pi_{t+1}^{I}+\delta$ using $\mathrm{n}=4, \mu=0.63, \pi^{T}=2$ and $\delta=1.05$ based on the estimates in column (iv) of Table 2. The inflation effect is equal to $\rho_{\pi t}=\theta_{t} \rho_{Z D}+\left(1-\theta_{t}\right) \rho_{O Z D}$. LHS axis for Figure 3b: measurement units of the inflation effect; RHS axis: measurement units of the interest rate. 